\title{
In comparison with palm oil, dietary nut supplementation delays the progression of atherosclerotic lesions in female apoE-deficient mice
}

\author{
Joaquín C. Surra ${ }^{1,2}$, Cristina Barranquero ${ }^{2,3}$, María P. Torcal ${ }^{3}$, Israel Orman ${ }^{4}$, Jose C. Segovia ${ }^{4}$, \\ Natalia Guillén ${ }^{2,3}$, María A. Navarro ${ }^{2,3}$, Carmen Arnal $^{2,5}$ and Jesús Osada ${ }^{2,3 *}$ \\ ${ }^{1}$ Departamento de Producción Animal, Escuela Politécnica Superior de Huesca, Huesca, Spain \\ ${ }^{2}$ CIBER de Fisiopatología de la Obesidad y Nutrición, Instituto de Salud Carlos III, Madrid, Spain \\ ${ }^{3}$ Departamento de Bioquimica y Biología Molecular y Celular, Facultad de Veterinaria, Instituto de Investigación Sanitaria \\ de Aragón, Universidad de Zaragoza, Zaragoza, Spain \\ ${ }^{4}$ Differentiation and Cytometry Unit, Hematopoiesis and Gene Therapy Division, Centro de Investigaciones Energéticas, \\ Medioambientales y Tecnológicas (CIEMAT) and Centro de Investigación Biomédica en Red de Enfermedades Raras \\ (CIBERER), Madrid, Spain \\ ${ }^{5}$ Departamento de Patología Animal, Facultad de Veterinaria, Universidad de Zaragoza, Zaragoza, Spain
}

(Submitted 1 November 2011 - Final revision received 8 February 2012 - Accepted 8 February 2012)

\begin{abstract}
Epidemiological studies have demonstrated the benefits of nut consumption on cardiovascular risk factors and CHD, attributed to their fatty acid profile, rich in unsaturated fatty acids, and also to other nutrients. The effect of nuts on atherosclerotic lesions was studied in female and male apoE-knockout mice fed a diet supplemented with $3 \%(\mathrm{w} / \mathrm{w})$ mixed nuts (mix: almonds, hazelnuts and walnuts in a proportion of $0 \cdot 25: 0 \cdot 25: 0 \cdot 50$, respectively), and compared with mice receiving an isoenergetic diet of similar fat content provided as palm oil. After 12 weeks, plasma lipid parameters and aortic lesions were measured. Males receiving nuts had lower plasma cholesterol than the palm oil group, and both sex groups had lower plasma non-HDL-cholesterol and lower content of reactive oxygen species in LDL than mice receiving the palm oil diet, the latter decrease being more pronounced in females than in males. Females consuming the nut diet showed a smaller aortic lesion area than those consuming palm oil, whereas no differences were observed in males. In females, hepatic paraoxonase 2 (Pon2) mRNA increased, and no change was observed in prenylcysteine oxidase 1 (Pcyox1) expression after the consumption of the nut-containing diet. In addition, aortic atherosclerotic lesions correlated directly with total plasma cholesterol and inversely with hepatic Pon 2 expression. The results suggest that the beneficial effect of nut intake in female apoE-deficient mice may be attributed to reduced non-HDL-cholesterol levels and enhanced PON2 antioxidant activity.
\end{abstract}

Key words: Nuts: ApoE-deficient mice: Atherosclerosis: Lipoproteins

CVD, as a result of an atherosclerotic process, are the leading cause of morbidity and mortality in developed countries, in which the diet is one of the most important environmental factors associated with the atherothrombotic process. However, epidemiological studies have shown a lower incidence of CHD in populations of Mediterranean countries ${ }^{(1,2)}$, a circumstance that could be attributed to the beneficial health effects of the so-called Mediterranean $\operatorname{diet}^{(3)}$, which is characterised by a high intake of vegetables, legumes, fruits and nuts, together with a widespread use of olive oil ${ }^{(4)}$. Nowadays, it is recognised that many of the nutrients in these foods have some protective effects against the atherogenic process. In the Mediterranean region, three nuts (walnuts, almonds and hazelnuts) are used to constitute part of the dietary source of energy, but have not been included in many dietary recommendations due to their high fat content ${ }^{(5-7)}$. Nevertheless, recent clinical evidence suggests that consumption of nuts promotes a healthy lipid profile associated with a lower risk of $\mathrm{CVD}^{(8-16)}$. Several studies have attributed this quality to their nutrients, mainly their MUFA and PUFA. Apart from that, nuts are complex foods that are sources of other nutrients: vegetable protein, fibre, vitamins, minerals and many bioactive constituents such as antioxidants, phytosterols and other phytochemicals ${ }^{(6,17)}$. To provide an experimental understanding of the results of epidemiological studies in human subjects and to tackle the possible beneficial mechanisms of

Abbreviations: ITGA4, integrin $\alpha 4$; ITGAM, integrin $\alpha \mathrm{M}$; Pcyox1, prenylcysteine oxidase 1; Pon2, Paraoxonase 2.

*Corresponding author: Dr J. Osada, fax +34976 761 612, email josada@unizar.es 
nut intake in atherosclerotic lesions, apoE-deficient mice were used in the present experimental study. The animals in this model develop spontaneous atherosclerosis, even with lowfat and low-cholesterol diets, and the disease features are similar to those observed in humans and other species ${ }^{(18)}$. Therefore, the aim of the present study was to compare the effect of supplementation with a mixture of three nuts on the development of atherosclerotic lesions with that of an isoenergetic diet containing palm oil in apoE-deficient mice.

\section{Materials and methods}

\section{Animals}

Female and male apoE-deficient mice ( $n 23$ each group), aged $2 \cdot 7$ (sem 0.03) months from a C57BL/6J $\times$ Ola129 genetic background, were fasted for $6 \mathrm{~h}$ and anaesthetised with isoflurane (Forane), and their blood was drawn from the retro-orbital plexus. Then, plasma cholesterol was determined. For each sex, two groups with similar plasma cholesterol concentrations were established. The animals had free access to food and water during the 12-week experimental period, and they were housed in a temperature-controlled facility and handled observing the criteria from the European Union for care and use of laboratory animals in research. The protocol was approved by the Ethics Committee for Animal Research of the University of Zaragoza.

\section{Diets}

In the present study, we established two study groups, one of which received a chow diet (Teklad Mouse/Rat Diet no. 2014, Harlan Teklad; Harlan Ibérica) supplemented with 3\% (w/w) edible whole nuts (nut group) in a mix composed of $50 \%$ walnuts, $25 \%$ almonds and $25 \%$ hazelnuts ( $n 11$ for both female and male mice). This represents a daily dose of $3 \mathrm{~g}$ nuts $/ \mathrm{kg}$ body weight per mouse which, considering the higher metabolic rate of mice ${ }^{(19)}$, would translate into the dose of $30 \mathrm{~g} / \mathrm{d}$ or $0.4 \mathrm{~g}$ nuts $/ \mathrm{kg}$ used in human interventions and the same proportion of nuts, so as to reproduce in mice the effects observed in human subjects ${ }^{(20-22)}$. The other group received the same chow diet but was supplemented with $2 \%(\mathrm{w} / \mathrm{w})$ palm oil. Both diets were isoenergetic and provided the same amount of fat and MUFA (Table 1). Diets were prepared by milling the chow diet, adding the corresponding supplement and $3.0 \%(\mathrm{w} / \mathrm{w})$ of wheat starch as agglutinant to facilitate pellet formation, and then drying at $60^{\circ} \mathrm{C}$ for $48 \mathrm{~h}$. All diets were prepared weekly and stored in an $\mathrm{N}_{2}$ atmosphere at $-20^{\circ} \mathrm{C}$. Fresh food was provided daily. Preparation of extractable and non-extractable phenolic compounds from the diets was carried out according to Arranz et al. ${ }^{(23)}$ and quantified using the method of Singleton et $_{\text {al }}{ }^{(24)}$. The contents of extractable phenolic compounds and hydrolysable polyphenols were higher (21 and 26\%, respectively) in the nut diet than in the palm oil diet (Table 1). The animals were fed the experimental diets for 12 weeks; both were well tolerated.

\section{Experimental procedures}

At 1 week before killing and after fasting, blood samples were obtained for integrin $\alpha \mathrm{M}$ (ITGAM) and integrin $\alpha 4$ (ITGA4) expressions and paraoxonase activity. At killing, the animals were euthanised by suffocation with $\mathrm{CO}_{2}$ and exsanguinated by cardiac puncture. The liver was split; one piece was stored in neutral buffered formaldehyde for histological analysis and the remainder immediately frozen in liquid $\mathrm{N}_{2}$. The heart and the arterial tree were perfused with $5 \mathrm{ml}$ of cold PBS ( $\mathrm{pH} 7 \cdot 4)$ under physiological pressure. After that, the heart was removed, embedded in $\mathrm{OCT}^{\mathrm{TM}}$ (Tissue-Tek), frozen in dry icecooled isopentane (Panreac) and stored at $-80^{\circ} \mathrm{C}$ until analysis.

\section{Plasma analysis}

Total plasma cholesterol and TAG concentrations were measured in a microtitre assay, using Infinity ${ }^{\mathrm{TM}}$ commercial kits (Thermo Scientific). Plasma HDL-cholesterol was quantified in the supernatant by a fluorometric enzyme assay (Amplex Red; Molecular Probes) after precipitation of apoB particles with phosphotungstic acid- $\mathrm{MnCl}_{2}$ (Roche). Paraoxonase was assayed as arylesterase activity determined by the rate of phenylacetate hydrolysis, as described previously ${ }^{(25)}$. ApoA1 and apoA4 were quantified by ELISA using specific polyclonal antibodies (Biodesign and Santa Cruz Biotechnology), as described previously ${ }^{(26)}$. Plasma lipoprotein profile was determined in $100 \mu$ l of pooled plasma samples from each group by fast protein liquid chromatography gel filtration ${ }^{(27)}$ using a Superose 6B column (Amersham Pharmacia), and the cholesterol in each fraction was measured with the fluorescent method described above.

Table 1. Characteristics of the experimental diets

\begin{tabular}{lcc}
\hline & Nut & Palm oil \\
\hline Metabolisable energy (MJ/kg) & $13 \cdot 2$ & $13 \cdot 4$ \\
Total fat (\% feed) & $5 \cdot 7$ & $5 \cdot 8$ \\
Fatty acid content (\% fat) & $15 \cdot 0$ & $27 \cdot 7$ \\
SFA & $26 \cdot 9$ & $27 \cdot 5$ \\
MUFA & $58 \cdot 1$ & 44.9 \\
PUFA & $3 \cdot 9$ & $1 \cdot 6$ \\
P:S ratio & 17 & 14 \\
Phenolic compounds ( $\mu$ mol caffeic acid equivalents/g) & 1300 & 1300 \\
Extractable & 335 & 266 \\
Non-extractable proanthocyanidins & & \\
Hydrolysable polyphenols & &
\end{tabular}

$\mathrm{P}: \mathrm{S}$, polyunsaturated:saturated ratio. 


\section{Blood cell analysis}

Expression of ITGAM and ITGA4 proteins in blood cells from samples taken 1 week before killing was analysed using a fluorescence-activated cell sorter (Becton-Dickinson), as described previously ${ }^{(28)}$. The results are expressed as the proportion (\%) of the marker-positive cells recovered in the region corresponding to monocytes.

\section{LDL oxidation susceptibility}

LDL oxidisability was assessed using modified procedures of Navab et $a l^{(29)}$ to determine the presence of reactive oxygen species by measuring the conversion of $2^{\prime}, 7^{\prime}$-dichlorofluorescein diacetate into fluorescent dichlorofluorescein. Briefly, LDL fractions ( $5 \mu \mathrm{g}$ cholesterol) separated by fast protein liquid chromatography were incubated, at $37^{\circ} \mathrm{C}$ with $2 \mu \mathrm{g}$ dichlorofluorescein, in $25 \mu \mathrm{l}$ of $0 \cdot 1 \%$ sodium azide and $100 \mu \mathrm{l}$ PBS, up to a total volume of $150 \mu$ l. Fluorescence was measured after $3 \mathrm{~h}$ of incubation at an excitation wavelength of $485 \mathrm{~nm}$ and an emission wavelength of $535 \mathrm{~nm}^{(30)}$.

\section{Evaluation of atherosclerotic lesions}

Sections of the proximal aorta from the frozen heart were sliced on a cryostat (Microm HM505E; Thermo Scientific). From each heart, four cryosections $(6 \mu \mathrm{m})$ were fixed with neutral buffered formaldehyde, stained for lipids with Sudan IV and counterstained with haematoxylin and eosin (Harris solution; Sigma Chemical Company). Images were captured by a digital camera fitted to a Nikon microscope. Aortic lesion areas were blindly quantified using Scion Image software (Scion Corporation).

\section{Hepatic histological analysis}

Liver samples stored in formaldehyde were embedded in paraffin. Then, sections $(4 \mu \mathrm{m})$ were stained with haematoxylin and eosin and images were captured. Hepatic fat content was evaluated by quantifying the lipid droplets in each liver section with Adobe Photoshop CS2 (Adobe Systems Incorporated) and expressed as a percentage of the entire liver section ${ }^{(31)}$.

\section{RNA isolation}

RNA was isolated using TRI Reagent Solution (Ambion; Applied Biosystems). Contaminant DNA was removed by TURBO DNA-free ${ }^{\mathrm{TM}}$ DNase treatment and removal reagents from Ambion. RNA was quantified by absorbance at $A_{260 / 280}$ (the $A_{260 / 280}$ ratio was greater than 1.75 ). The integrity of $28 \mathrm{~S}$ and $18 \mathrm{~S}$ ribosomal RNA was verified by agarose gel electrophoresis followed by ethidium bromide staining, and the 28S:18S ratio was greater than 2 .

\section{Quantification of mRNA}

Equal amounts of DNA-free RNA from each sample of all animals were used in quantitative RT-PCR analyses. First-strand complementary DNA synthesis and PCR were performed using the First-Strand complementary DNA Synthesis Kit (Fermentas) and Power SYBR $®$ Green PCR Master Mix (Applied Biosystems) according to the manufacturers' instructions and as described previously ${ }^{(32)}$. Primers were designed by Primer Express ${ }^{\circledR}$ (Applied Biosystems) and checked by BLAST analysis (NCBI) to verify specificity and selective amplification of the target gene, as well as to ensure amplification of complementary DNA and not of genomic DNA. The sequences were as follows: for Pla2g 7 - sense, 5'-GCG TTT GTA CTA CCC AGC TCA AGA-3', antisense, 5'-TGC AGG AGT TGT CAG AGA ACCA- $3^{\prime}$; for prenylcysteine oxidase 1 (Pcyox 1 ) - sense, 5'-GGT TCA GTC ATT CAC CCC CTA A-3', antisense, 5'-TAC AAA CCA GCT GCT CTC CTC A-3'; for paraoxonase 2 (Pon2) - sense, 5'-GCA CGC TGG TGG ACA ATT TATC-3', antisense, 5'-TGT CAC TGAT GGC TTC TCG GAT- $3^{\prime}$. Real-time PCR were performed in an ABI PRISM 7700 Sequence Detector (Applied Biosystems) following the standard procedure. The specificity of the PCR was confirmed by observing a single dissociation curve. The relative amount of all mRNA was calculated using the comparative $2^{-\Delta \Delta C \mathrm{q}}$ method. Ppib mRNA was used as the reference gene ${ }^{(33)}$.

\section{Statistical analyses}

Data were analysed by the Kolmogorov-Smirnov test to check for the normal distribution of variables and by Bartlett's test to assess the homogeneity of variance. Student's $t$ test was used when both tests satisfied the corresponding hypothesis, and when either of these tests did not, differences between pairs were tested using the Mann-Whitney $U$ test. Unless otherwise stated, results are presented as means with their standard errors. Correlations between variables were tested by calculating Spearman's correlation coefficient using SPSS software, version 15.0 (SPSS, Inc.). Differences were considered significant when $P<0 \cdot 05$.

\section{Results}

\section{Body and liver weight}

Somatic variables in the animals are shown in Table 2. At killing, males and females had significant differences in body weight $(P<0 \cdot 001)$ and body-weight changes $(P=0 \cdot 01)$. However, we found no significant differences between the two diets in terms of body-weight change, liver weight, feed intake or energy intake.

\section{Plasma lipid parameters}

The effect of the different diets on plasma lipid parameters after the 12-week experimental period is shown in Table 3. The same-sex groups had similar initial cholesterol levels, which were significantly higher in males than in females, and this difference remained after the experimental period. In females, no significant differences were observed between the two diets in terms of total cholesterol. However, male mice consuming the nut diet had significantly lower plasma cholesterol than those in the palm oil group. There were no

complementary DNA synthesis and PCR were performed 
Table 2. Effect of the experimental diets on somatic variables in apoE-knockout mice (Mean values with their standard errors)

\begin{tabular}{|c|c|c|c|c|c|c|c|c|}
\hline & \multicolumn{4}{|c|}{ Female } & \multicolumn{4}{|c|}{ Male } \\
\hline & \multicolumn{2}{|c|}{ Nut* $^{*}(n 12)$} & \multicolumn{2}{|c|}{ Palm oil $(n 11)$} & \multicolumn{2}{|c|}{ Nut $^{\star}(n 11)$} & \multicolumn{2}{|c|}{ Palm oil $(n 12)$} \\
\hline & Mean & SEM & Mean & SEM & Mean & SEM & Mean & SEM \\
\hline Final body weight $(\mathrm{g})$ & $20 \cdot 2$ & 0.5 & $20 \cdot 3$ & 0.7 & $22 \cdot 4$ & 0.4 & $22 \cdot 0$ & 0.6 \\
\hline Body-weight change (g) & $3 \cdot 2$ & 0.4 & 3.4 & 0.3 & $2 \cdot 3$ & 0.4 & $2 \cdot 8$ & 0.2 \\
\hline Liver weight (g) & $0 \cdot 88$ & 0.03 & 0.82 & 0.04 & 0.87 & 0.03 & $0 \cdot 82$ & 0.03 \\
\hline Liver:body weight (\%) & 4.4 & $0 \cdot 1$ & 4.0 & $0 \cdot 1$ & 3.9 & $0 \cdot 1$ & 3.7 & 0.1 \\
\hline Food intake $(g / d)$ & 3.2 & 0.1 & 2.9 & 0.1 & 3.6 & $0 \cdot 1$ & 3.5 & $0 \cdot 1$ \\
\hline Metabolisable energy intake $(\mathrm{kJ} / \mathrm{d})$ & $42 \cdot 7$ & $2 \cdot 7$ & 38.7 & $2 \cdot 8$ & $47 \cdot 8$ & 1.5 & $47 \cdot 7$ & $2 \cdot 2$ \\
\hline
\end{tabular}

significant differences in plasma HDL-cholesterol in the two dietary groups. VLDL + LDL-cholesterol were significantly lower in mice of both sexes receiving the nut diet. Plasma TAG levels were higher $(P<0.001)$ in males than in females, but neither sex showed significant diet-related differences. ApoA1, the principal protein in HDL particles, and in agreement with the results for HDL-cholesterol, was not modified by the dietary intervention. ApoA4 was significantly decreased in males on the nut diet. A significant increase was observed in arylesterase activity in female mice receiving the nut diet.

\section{Monocyte activation}

ITGAM and ITGA4 protein expressions of circulating monocytes are also shown in Table 3. The percentages of monocytes expressing ITGAM and ITGA4 showed no significant differences between the diets in either sex.

\section{Quantification of atherosclerotic lesion area}

Fig. 1 shows the atherosclerotic lesion area in apoE-knockout mice consuming the different diets. After consumption of a diet supplemented with nuts or palm oil for 12 weeks, the aortic atherosclerotic lesion areas tended to show higher values in males than in females, although the difference did not reach statistical significance (94.1 (SEM 12.0) $v$. 70.8 (sEM 7.3) $\times 10^{3} \mu \mathrm{m}^{2}, P<0 \cdot 11$ ). A sex-related difference in the pattern of response to the different diets was noted; while female mice fed the nut diet showed significantly lower values than those on the palm oil diet, this effect was not observed in males receiving the same diets. Moreover, males consuming the nut diet showed two types of response: one group of mice $(n 6)$ presented a marked reduction in lesion area (34.5 (sEM

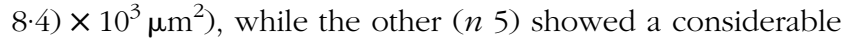
increase $(158.5$ (SEM 9.6$) \times 10^{3} \mu \mathrm{m}^{2}$ ), suggesting an individual genetic response to nut supplementation.

\section{Oxidative stress variables}

As shown in Fig. 2(a), LDL prepared from the nut groups showed significantly lower levels of reactive oxygen species than LDL from palm oil-fed animals in both sexes. The decrease was particularly important in females.

Table 3. Effect of dietary intervention on plasma parameters in apoE-knockout mice according to sex (Mean values with their standard errors)

\begin{tabular}{|c|c|c|c|c|c|c|c|c|}
\hline & \multicolumn{4}{|c|}{ Female } & \multicolumn{4}{|c|}{ Male } \\
\hline & \multicolumn{2}{|c|}{ Nut† $(n$ 12) } & \multicolumn{2}{|c|}{$\begin{array}{c}\text { Palm oil ( } n \\
11)\end{array}$} & \multicolumn{2}{|c|}{ Nut† $(n 11)$} & \multicolumn{2}{|c|}{$\begin{array}{c}\text { Palm oil ( } n \\
12)\end{array}$} \\
\hline & Mean & SEM & Mean & SEM & Mean & SEM & Mean & SEM \\
\hline Initial cholesterol (mmol/l) & $12 \cdot 9$ & 0.6 & $12 \cdot 1$ & 0.7 & $17 \cdot 3$ & $1 \cdot 2$ & $16 \cdot 5$ & 0.9 \\
\hline Total cholesterol (mmol/l) & $9 \cdot 1$ & 0.8 & $10 \cdot 8$ & 0.9 & $14 \cdot 0$ & $1 \cdot 2$ & $17 \cdot 1$ & $0.9^{*}$ \\
\hline HDL-cholesterol (mmol/l) & 0.11 & 0.04 & 0.14 & 0.03 & 0.11 & 0.03 & $0 \cdot 10$ & 0.01 \\
\hline VLDL- + LDL-cholesterol (mmol/l) & 8.5 & 0.7 & $10 \cdot 6$ & $0.9^{*}$ & 13.9 & $1 \cdot 2$ & $17 \cdot 0$ & $0.9^{*}$ \\
\hline TAG $(\mathrm{mmol} / \mathrm{l})$ & $2 \cdot 0$ & 0.2 & 1.9 & 0.1 & 3.0 & 0.3 & $3 \cdot 2$ & 0.2 \\
\hline ApoA1 (AU) & 110 & 6 & 112 & 6 & 96 & 7 & 101 & 8 \\
\hline ApoA4 (AU) & 41 & 3 & 37 & 4 & 30 & 3 & 39 & $3^{*}$ \\
\hline Arylesterase activity $\left(\times 10^{3} \mu \mathrm{mol} / \mathrm{min}\right.$ per I) & $12 \cdot 2$ & 0.5 & $10 \cdot 3$ & $0.8^{*}$ & $10 \cdot 6$ & 0.5 & $11 \cdot 8$ & 0.5 \\
\hline ITGAM $\ddagger$ (\% monocytes) & 24.4 & 1.5 & $25 \cdot 7$ & 1.7 & $27 \cdot 3$ & 1.4 & $26 \cdot 2$ & 2.4 \\
\hline ITGA4‡ (\% monocytes) & 78.5 & $2 \cdot 5$ & $81 \cdot 1$ & 1.9 & $76 \cdot 6$ & 1.6 & 74.9 & $3 \cdot 3$ \\
\hline
\end{tabular}

AU, arbitrary units; ITGAM, integrin $\alpha \mathrm{M}$; ITGA4, integrin $\alpha 4$.

* Mean values were significantly different from those of the nut diets $(P<0.05$; Mann-Whitney $U$ test $)$.

† Nut, diet supplemented with $3 \%$ nuts, composed of $50 \%$ walnuts, $25 \%$ almonds and $25 \%$ hazelnuts

‡ITGAM and ITGA4 protein levels are shown. 


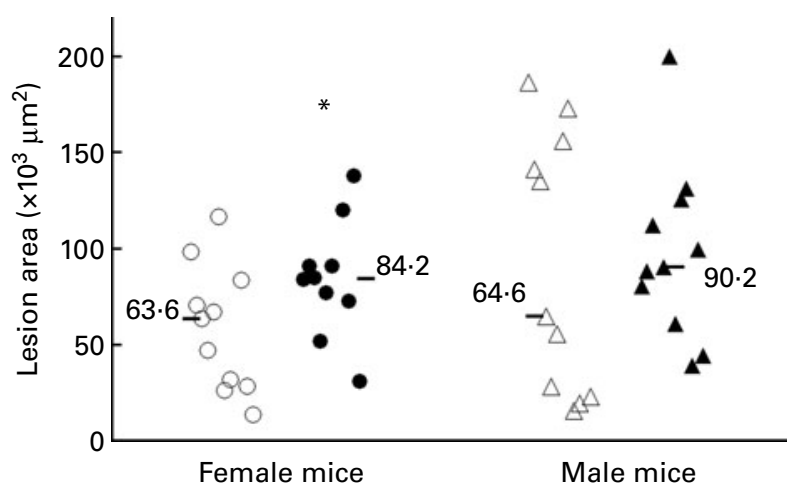

Fig. 1. Effect of supplementation with nuts or palm oil on aortic atherosclerotic lesions in apoE-knockout mice according to sex. Blinded quantification of atherosclerotic lesion areas was carried out in aortic cross-sections from female mice receiving the nut $(0)$ and palm oil $(\bullet)$ diets and male mice receiving the nut $(\Delta)$ and palm oil $(\boldsymbol{\Delta})$ diets, respectively. Individual data and medians are shown. * Median values were significantly different from those of the nut diet $(P=0.05$; Mann-Whitney $U$ test $)$.

Since PON2 is a ubiquitous antioxidant enzyme ${ }^{(34)}$, we investigated whether the test diets induced any differential hepatic mRNA expression. According to the results depicted in Fig. 2(b), female mice consuming the nut diet showed a significant increase in the hepatic expression of this message. On the other hand, the hepatic mRNA expression of Pcyox1 (a pro-oxidant enzyme of $\mathrm{LDL}^{(35)}$ ) was also tested (Fig. 2(c)), and no change was observed in females, while it increased in males consuming the nut diet.

\section{Association among parameters}

In an association analysis including all animals, atherosclerotic lesion areas showed a positive relationship with plasma cholesterol concentrations $(r 0.49, P=0.001)$. When the two sexes were analysed separately, this association was stronger in females $(r 0 \cdot 71, P=0.00$; Fig. 3(a)). Likewise, a significant inverse association was observed between atherosclerotic lesion areas and hepatic Pon 2 mRNA expression $(r-0.55$, $P=0 \cdot 02$; Fig. 3(b)).

\section{Discussion}

Atherosclerotic lesions in female and male apoE-deficient mice showed differential responses to a diet supplemented with 3\% mixed nuts compared with a diet with a similar contribution of fat provided by palm oil (saturated fat). In both sexes, the addition of a small amount of nuts decreased non-HDL-cholesterol and the content of reactive oxygen species in LDL. However, an increase in serum paraoxonase activity and in the hepatic expression of Pon 2 was observed only in females consuming the nut diet. The decrease in atherosclerotic lesion areas was significant and correlated positively with plasma cholesterol and negatively with Pon2 expression. These results indicate that female mice benefit from nut intake, as it lowers their LDL and endows them with a higher antioxidant defence through PON2.
The decreased non-HDL-cholesterol in males and females on the nut diet compared with the saturated fat-enriched diet, palm oil in this case, agrees with numerous human clinical studies that have consistently shown a favourable plasma lipid response to diets including almonds, hazelnuts or walnuts ${ }^{(8,9,11-16)}$. The beneficial effects of nuts on the lipid profile are mainly attributed to their favourable fatty acid composition - low in saturated and high in unsaturated fatty acids. In the present experiment, the nut supplement contributed to the increase in the PUFA content of this diet, leading to a higher and more favourable polyunsaturated:saturated
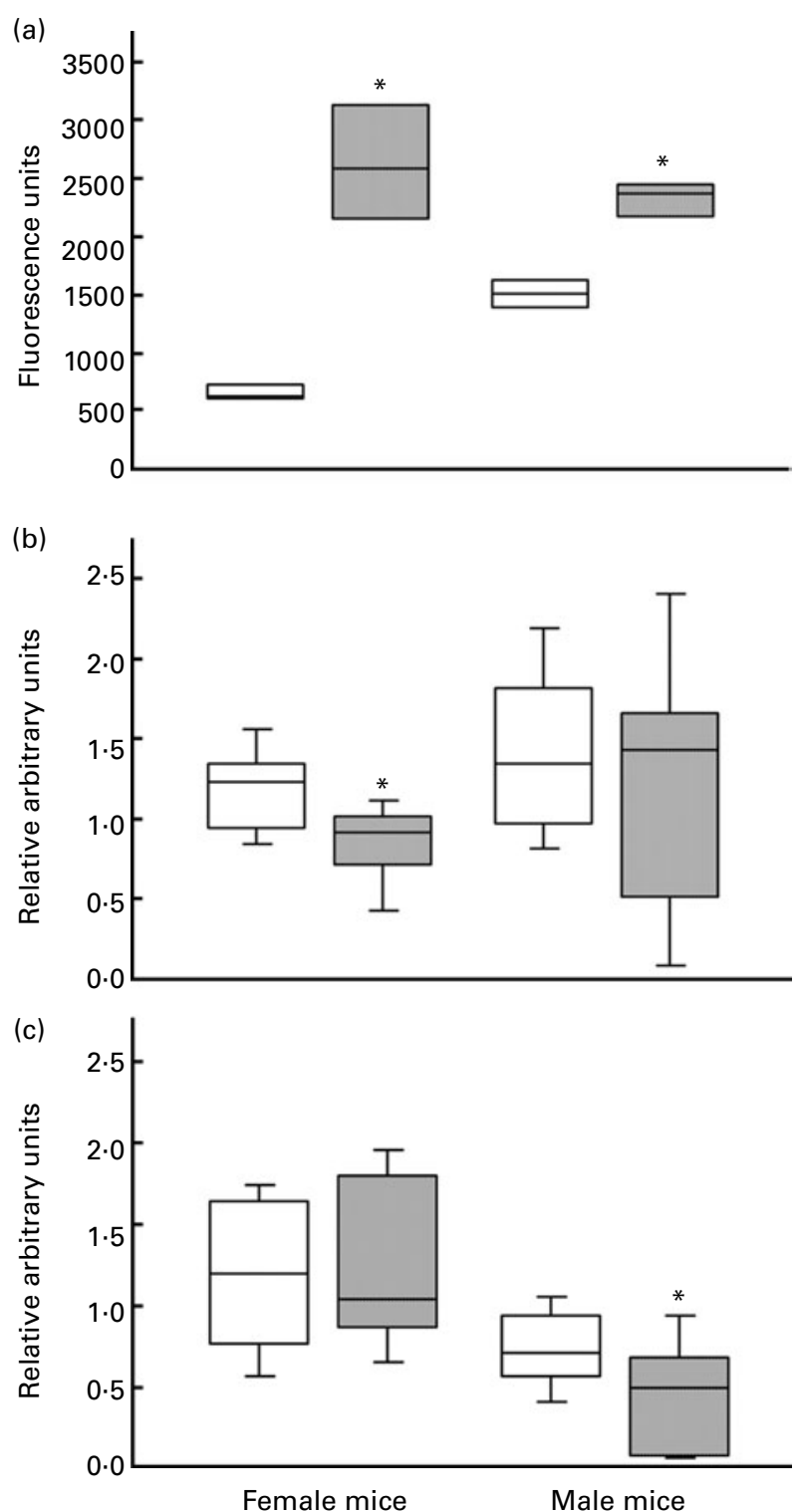

Fig. 2. Effect of supplementation with nuts $(\square)$ or palm oil ( $\square$ ) on LDL reactive oxygen species (ROS) content and hepatic paraoxonase 2 (Pon2) and prenylcysteine oxidase 1 (Pcyox1) mRNA expressions according to sex. (a) Presence of ROS in LDL prepared from the different experimental groups and assayed as described in the Materials and methods section. (b) Hepatic Pon2 mRNA expression. (c) Hepatic Pcyox1 mRNA expression. Data are presented as box plots showing medians and interquartile ranges. * Median values were significantly different from those of the nut diet $(P<0.05$; MannWhitney comparison between pairs). 
(a)

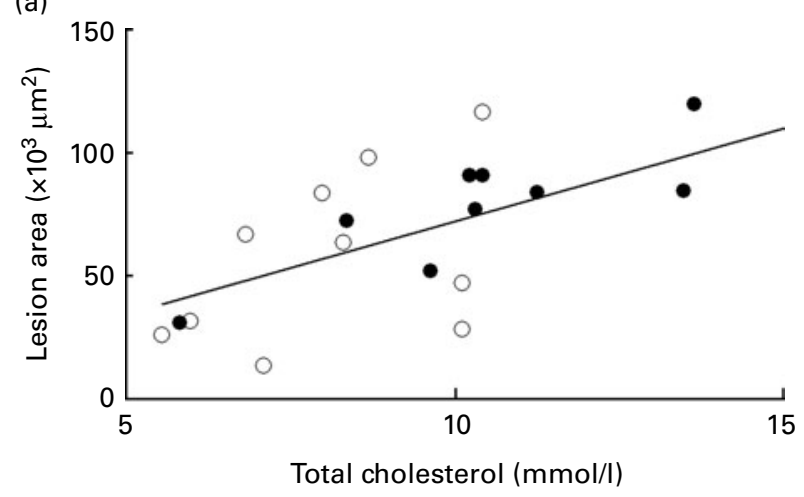

(b)

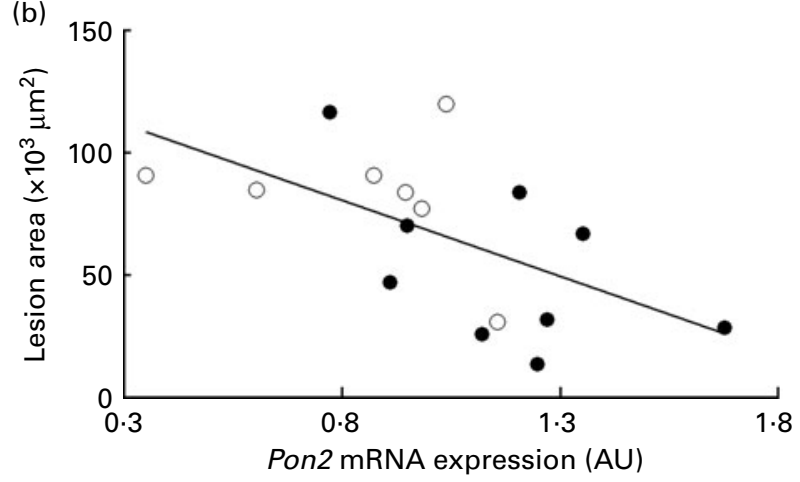

Fig. 3. Relationships among parameters in female apoE-deficient mice consuming the different diets. (a) Relationship between the atherosclerotic lesion area and total cholesterol $\left(R_{\mathrm{s}}=0.71 ; P=0.00\right)$. (b) Association between the atherosclerotic lesion area and hepatic paraoxonase 2 (Pon2) mRNA expression $\left(R_{\mathrm{s}}=-0.55 ; P=0.02\right)$. Correlations were calculated according to Spearman's test and values corresponding to all experimental groups have been included where $O$ and $O$ correspond to the nut and palm oil groups, respectively. $\mathrm{AU}$, arbitrary units.

ratio than palm oil (3.9 v. 1.6, respectively; Table 1 ). The decrease in plasma cholesterol produced by a high PUFA in comparison with a saturated fat diet has also been reported in male apoE-deficient mice ${ }^{(27)}$, in both sexes in LDL receptorand apoE-deficient mice ${ }^{(36)}$, in male rabbits ${ }^{(37)}$ and in male hamsters ${ }^{(38)}$. Therefore, using this experimental design, nonHDL-cholesterol in apoE-deficient mice fed nuts follows the human pattern and could be attributed to the fatty acid composition of the diets.

With respect to the finding of a lack of effect on HDLcholesterol, or on its main apoA1, human studies involving diets enriched in almonds, hazelnuts or walnuts have also shown contradictory results, reporting increases ${ }^{(8,11,14)}$, decreases $^{(12)}$ or absence of changes ${ }^{(13,39)}$. Furthermore, there is no agreement on the effect of PUFA-containing diets on plasma HDL-cholesterol in animal studies: PUFA tend to reduce HDL-cholesterol in rabbits receiving a diet enriched with maize oil compared with olive or avocado oil ${ }^{(37)}$, but tend to increase it in comparison with coconut oil. Meanwhile in male hamsters, the substitution of maize oil as a source of polyunsaturated fat for palm oil decreased HDL-cholesterol $^{(38)}$. Moreover, a different HDL response to diets has been reported in LDL receptor- and apoE-deficient mice, two models of atherosclerosis ${ }^{(36)}$. While apoE-deficient mice consuming PUFA diets compared with diets containing SFA showed decreased HDL-cholesterol in females as well as in males, no differences were observed between these diets in terms of plasma HDL in LDL receptor-deficient mice of either sex. Overall, these results point to an interaction among dietary composition, sex and genetic background that makes dietary response complex.

In the present study, there were sex-related differences in the response of atherosclerotic lesions to dietary nut supplementation, a circumstance that does not seem to be the case in human studies dealing with risk factors ${ }^{(16,40)}$ or in an intervention analysing carotid atherosclerosis ${ }^{(41)}$. Despite the fact that we used the same proportion of nuts as the latter study, we should point out the differences between the two reports, including the analysis of different arteries and the particular lipid metabolism in apoE-deficient mice ${ }^{(18)}$, which, moreover, exhibit clear differences between sexes ${ }^{(27,42)}$. In females, the nut-supplemented diet delayed the progression of aortic lesions compared with palm oil, a finding that may be attributed to a synergistic effect on plasma non-HDL-cholesterol levels, on the one hand, and on increased antioxidant defence of LDL, on the other hand. The latter could be executed through an increase in Pon2 expression as an ubiquitous antioxidant enzyme $^{(34)}$ and without any change in Pcyox 1 , the pro-oxidant agent of these particles ${ }^{(35)}$. In fact, PON2 has been shown to protect against atherosclerosis development ${ }^{(43-46)}$. In addition, its expression could also be modified by sex as occurs with Pon1, another member of the three-gene paraoxonase family $^{(47)}$.

Favourable effects of nuts may be attributed to their fatty acid profiles or the presence of other minor components. One limitation of our experimental design using palm oil for comparison is the inability to discriminate between the two components, but a positive aspect is that it proposes a practical and reasonable combination to be recommended for populations. Indirectly, the changes observed in hepatic Pon2 gene expression cannot be explained by the different fatty acid profile. In macrophages, this enzyme has been induced by polyphenols from pomegranate ${ }^{(48)}$, and some of these substances are also present in walnuts, but not in hazelnuts or almonds ${ }^{(49)}$. In fact, our nut diet provides a higher amount of hydrolysable polyphenols. Therefore, the present observation would represent an initial contribution to defining a role for these compounds in the regulation of PON2 via its mRNA and possibly in mediating LDL reactive oxygen species content. Several observations suggest that nut antioxidants have favourable effects on $\mathrm{CVD}^{(50)}$. Indeed, ellagic acid and polyphenol-rich extracts from walnuts were effective inhibitors of in vitro plasma LDL oxidation ${ }^{(51,52)}$, and flavonoids from the almond peel protected LDL from oxidation in hamsters $^{(53)}$. However, other authors have found no differences in plasma antioxidant status following walnut consumption, despite an increase in thiols ${ }^{(49)}$, nor have Bullo et al. ${ }^{(54)}$ observed differences between walnuts and walnut-skin extracts. In this respect, despite the slightly high hydrolysable polyphenol content of the nut diet, the different response observed in females may also be attributed to possible differences in nut polyphenol species with respect to palm oil, and 
to combinations and interactions among them and with the matrix. Phenolic compounds may exert both anti- and prooxidant effects ${ }^{(55,56)}$. In this respect, Acin et al. ${ }^{(57)}$ reported that the oral administration of hydroxytyrosol to apoEdeficient mice increased the atherosclerotic lesion area, suggesting that phenolic compounds, outside the original matrix, could not only fail to be useful, but could even be harmful. Another source of variation is introduced by sex, which, in this species, modifies the response to exogenous factors and genetic background ${ }^{(42,58)}$. The clarification of these aspects will require further studies.

In conclusion, the present results in apoE-deficient mice show that, compared with consumption of a palm oil-enriched diet, consumption of a mixed nut diet is associated with decreased aortic atherosclerosis in females but not in males, an effect that appears to be related to both a reduction in non-HDL-cholesterol and an enhanced expression of Pon2 with protection of LDL from oxidation.

\section{Acknowledgements}

We thank Silvia Garcés and Mª Pilar Lierta for their help in maintaining the animals, and Belén Aguado and Asun Callizo for their contribution to diet preparation. We also thank Martha Messman for her assistance in manuscript editing. This study was funded by grants CICYT-FEDER (SAF201014958), Gobierno de Aragón (PI025/08) and Redes FSE-DGA (B-69). N. G. and M. A. N. were recipients of a Fundación Cuenca Villoro fellowship and a Miguel Servet contract, respectively. CIBER Fisiopatología de la Obesidad y Nutrición is an initiative of ISCIII. The contribution of each author was as follows: J. C. S. carried out the design of the diets, atherosclerotic analysis and prepared the manuscript; M. P. T. carried out apo analysis and prepared the manuscript; I. O. carried out the flow cytometer experiments; J. C. S. evaluated the flow cytometer experiments and prepared the manuscript; N. G. was involved in animal management and sample preparation; M. A. N. carried out plasma lipid analysis and statistical analysis; C. B. carried out apo analysis and prepared and analysed the mRNA expression; C. A. carried out the histological analyses; J. O. supervised the experimental design, obtained funding and prepared the manuscript. The authors report no conflicts of interest.

\section{References}

1. Keys A (1995) Mediterranean diet and public health: personal reflections. Am J Clin Nutr 61, 1321S-1323S.

2. Trichopoulos D \& Lagiou P (2004) Mediterranean diet and overall mortality differences in the European Union. Public Health Nutr 7, 949-951.

3. Trichopoulou A, Costacou T, Bamia C, et al. (2003) Adherence to a Mediterranean diet and survival in a Greek population. $N$ Engl J Med 348, 2599-2608.

4. Willett WC, Sacks F, Trichopoulou A, et al. (1995) Mediterranean diet pyramid: a cultural model for healthy eating. $A m J$ Clin Nutr 61, 1402S-1406S.

5. Fraser GE (1992) Nut consumption, lipids, and risk of a coronary event. Clin Cardiol 22, III11-III15.
6. Sabate J, Ros E \& Salas-Salvado J (2006) Nuts: nutrition and health outcomes. Preface. Br J Nutr 96, Suppl. 2, S1-S2.

7. Ros E \& Mataix J (2006) Fatty acid composition of nutsimplications for cardiovascular health. Br J Nutr 96, Suppl. 2, S29-S35.

8. Abbey M, Noakes M, Belling GB, et al. (1994) Partial replacement of saturated fatty acids with almonds or walnuts lowers total plasma cholesterol and low-density-lipoprotein cholesterol. Am J Clin Nutr 59, 995-999.

9. Durak I, Koksal I, Kacmaz M, et al. (1999) Hazelnut supplementation enhances plasma antioxidant potential and lowers plasma cholesterol levels. Clin Chim Acta 284, $113-115$.

10. Kris-Etherton PM, Zhao G, Binkoski AE, et al. (2001) The effects of nuts on coronary heart disease risk. Nutr Rev 59 , 103-111.

11. Jenkins DJ, Kendall CW, Marchie A, et al. (2002) Dose response of almonds on coronary heart disease risk factors: blood lipids, oxidized low-density lipoproteins, lipoprotein(a), homocysteine, and pulmonary nitric oxide: a randomized, controlled, crossover trial. Circulation 106, 1327-1332.

12. Sabate J, Fraser GE, Burke K, et al. (1993) Effects of walnuts on serum-lipid levels and blood-pressure in normal men. $N$ Engl J Med 328, 603-607.

13. Spiller GA, Jenkins DAJ, Bosello O, et al. (1998) Nuts and plasma lipids: an almond-based diet lowers LDL-C while preserving HDL-C. J Am Coll Nutr 17, 285-290.

14. Zambon D, Sabate J, Munoz S, et al. (2000) Substituting walnuts for monounsaturated fat improves the serum lipid profile of hypercholesterolemic men and women. A randomized crossover trial. Ann Intern Med 132, 538-546.

15. Griel AE \& Kris-Etherton PM (2006) Tree nuts and the lipid profile: a review of clinical studies. Br J Nutr 96, Suppl. 2, S68-S78.

16. Sabate J, Oda K \& Ros E (2010) Nut consumption and blood lipid levels: a pooled analysis of 25 intervention trials. Arch Intern Med 170, 821-827.

17. Kris-Etherton PM, Yu-Poth S, Sabate J, et al. (1999) Nuts and their bioactive constituents: effects on serum lipids and other factors that affect disease risk. Am J Clin Nutr 70, 504S-511S.

18. Sarria AJ, Surra JC, Acin S, et al. (2006) Understanding the role of dietary components on atherosclerosis using genetic engineered mouse models. Front Biosci 11, 955-967.

19. Demetrius L (2005) Of mice and men. When it comes to studying ageing and the means to slow it down, mice are not just small humans. EMBO Rep 6, S39-S44.

20. Estruch R, Martínez-González MA, Corella D, et al. (2006) Effects of a Mediterranean-style diet on cardiovascular risk factors: a randomized trial. Ann Intern Med 145, 1-11.

21. Fito M, Guxens M, Corella D, et al. (2007) Effect of a traditional Mediterranean diet on lipoprotein oxidation: a randomized controlled trial. Arch Intern Med 167, 1195-1203.

22. Salas-Salvado J, Fernandez-Ballart J, Ros E, et al. (2008) Effect of a Mediterranean diet supplemented with nuts on metabolic syndrome status: one-year results of the PREDIMED randomized trial. Arch Intern Med 168, 2449-2458.

23. Arranz S, Saura-Calixto F, Shaha S, et al. (2009) High contents of nonextractable polyphenols in fruits suggest that polyphenol contents of plant foods have been underestimated. J Agric Food Chem 57, 7298-7303.

24. Singleton VL, Orthofer R \& Lamuela-Raventós RM (1999) Analysis of total phenols and other oxidation substrates and antioxidants by means of folin-ciocalteu reagent. Meth Enzymol 299, 152-178. 
25. Acin S, Navarro MA, Carnicer R, et al. (2005) Dietary cholesterol suppresses the ability of olive oil to delay the development of atherosclerotic lesions in apolipoprotein E knockout mice. Atherosclerosis 182, 17-28.

26. Navarro MA, Carpintero R, Acin S, et al. (2005) Immuneregulation of the apolipoprotein A-I/C-III/A-IV gene cluster in experimental inflammation. Cytokine 31, 52-63.

27. Calleja L, Paris MA, Paul A, et al. (1999) Low-cholesterol and high-fat diets reduce atherosclerotic lesion development in ApoE-knockout mice. Arterioscler Thromb Vasc Biol 19, 2368-2375.

28. Acin S, Navarro MA, Perona JS, et al. (2007) Olive oil preparation determines the atherosclerotic protection in apolipoprotein E knockout mice. $J$ Nutr Biochem 18, 418-424.

29. Navab M, Hama SY, Hough GP, et al. (2001) A cell-free assay for detecting HDL that is dysfunctional in preventing the formation of or inactivating oxidized phospholipids. J Lipid Res 42, 1308-1317.

30. Arbones-Mainar JM, Navarro MA, Carnicer R, et al. (2007) Accelerated atherosclerosis in apolipoprotein E-deficient mice fed Western diets containing palm oil compared with extra virgin olive oils: a role for small, dense high-density lipoproteins. Atherosclerosis 194, 372-382.

31. Guillen N, Acin S, Navarro MA, et al. (2008) Squalene in a sex-dependent manner modulates atherosclerotic lesion which correlates with hepatic fat content in apoE-knockout male mice. Atherosclerosis 197, 72-83.

32. Arbones-Mainar JM, Navarro MA, Acin S, et al. (2006) Trans10, cis-12- and cis-9, trans-11-conjugated linoleic acid isomers selectively modify HDL-apolipoprotein composition in apolipoprotein E knockout mice. J Nutr 136, 353-359.

33. Guillen N, Navarro MA, Arnal C, et al. (2009) Microarray analysis of hepatic gene expression identifies new genes involved in steatotic liver. Physiol Genomics 37, 187-198.

34. Precourt LP, Amre D, Denis MC, et al. (2011) The three-gene paraoxonase family: physiologic roles, actions and regulation. Atherosclerosis 214, 20-36.

35. Banfi C, Brioschi M, Barcella S, et al. (2009) Proteomic analysis of human low-density lipoprotein reveals the presence of prenylcysteine lyase, a hydrogen peroxide-generating enzyme. Proteomics 9, 1344-1352.

36. Merkel M, Velez-Carrasco W, Hudgins LC, et al. (2001) Compared with saturated fatty acids, dietary monounsaturated fatty acids and carbohydrates increase atherosclerosis and VLDL cholesterol levels in LDL receptor-deficient, but not apolipoprotein E-deficient, mice. Proc Natl Acad Sci US A 98, 13294-13299.

37. Kritchevsky D, Tepper SA, Wright S, et al. (2003) Cholesterol vehicle in experimental atherosclerosis 24: avocado oil. $J \mathrm{Am}$ Coll Nutr 22, 52-55.

38. Terpstra AH, van den Berg P, Jansen H, et al. (2000) Decreasing dietary fat saturation lowers HDL-cholesterol and increases hepatic HDL binding in hamsters. Br J Nutr $\mathbf{8 3}$, 151-159.

39. Torabian S, Haddad E, Cordero-MacIntyre Z, et al. (2010) Long-term walnut supplementation without dietary advice induces favorable serum lipid changes in free-living individuals. Eur J Clin Nutr 64, 274-279.

40. Ros E, Tapsell LC \& Sabate J (2010) Nuts and berries for heart health. Curr Atheroscler Rep 12, 397-406.

41. Murie-Fernandez M, Irimia P, Toledo E, et al. (2011) Carotid intima-media thickness changes with Mediterranean diet: a randomized trial (PREDIMED-Navarra). Atherosclerosis 219, 158-162.
42. Surra JC, Guillen N, Arbones-Mainar JM, et al. (2010) Sex as a profound modifier of atherosclerotic lesion development in apolipoprotein E-deficient mice with different genetic backgrounds. J Atheroscler Thromb 17, 712-721.

43. Devarajan A, Bourquard N, Hama S, et al. (2011) Paraoxonase 2 deficiency alters mitochondrial function and exacerbates the development of atherosclerosis. Antioxid Redox Signal 14, 341-351.

44. Horke S, Witte I, Wilgenbus P, et al. (2007) Paraoxonase-2 reduces oxidative stress in vascular cells and decreases endoplasmic reticulum stress-induced caspase activation. Circulation 115, 2055-2064.

45. Reddy ST, Devarajan A, Bourquard N, et al. (2008) Is it just paraoxonase 1 or are other members of the paraoxonase gene family implicated in atherosclerosis? Curr Opin Lipidol 19, 405-408.

46. She ZG, Zheng W, Wei YS, et al. (2009) Human paraoxonase gene cluster transgenic overexpression represses atherogenesis and promotes atherosclerotic plaque stability in ApoE-null mice. Circ Res 104, 1160-1168.

47. Bin Ali A, Zhang Q, Lim YK, et al. (2003) Expression of major HDL-associated antioxidant PON-1 is gender dependent and regulated during inflammation. Free Radic Biol Med 34, 824-829.

48. Shiner M, Fuhrman B \& Aviram M (2007) Macrophage paraoxonase 2 (PON2) expression is up-regulated by pomegranate juice phenolic anti-oxidants via PPAR gamma and AP-1 pathway activation. Atherosclerosis 195, 313-321.

49. McKay DL, Chen CY, Yeum KJ, et al. (2010) Chronic and acute effects of walnuts on antioxidant capacity and nutritional status in humans: a randomized, cross-over pilot study. Nutr J 9, 21.

50. Blomhoff R, Carlsen MH, Andersen LF, et al. (2006) Health benefits of nuts: potential role of antioxidants. $\mathrm{Br} J$ Nutr 96, Suppl. 2, S52-S60.

51. Anderson KJ, Teuber SS, Gobeille A, et al. (2001) Walnut polyphenolics inhibit in vitro human plasma and LDL oxidation. J Nutr 131, 2837-2842.

52. Torabian S, Haddad E, Rajaram S, et al. (2009) Acute effect of nut consumption on plasma total polyphenols, antioxidant capacity and lipid peroxidation. J Hum Nutr Diet 22, 64-71.

53. Chen CY, Milbury PE, Lapsley K, et al. (2005) Flavonoids from almond skins are bioavailable and act synergistically with vitamins $\mathrm{C}$ and $\mathrm{E}$ to enhance hamster and human LDL resistance to oxidation. J Nutr 135, 1366-1373.

54. Bullo M, Nogues MR, Lopez-Uriarte P, et al. (2010) Effect of whole walnuts and walnut-skin extracts on oxidant status in mice. Nutrition 26, 823-828.

55. Filipe P, Haigle J, Silva JN, et al. (2004) Anti- and pro-oxidant effects of quercetin in copper-induced low density lipoprotein oxidation. Quercetin as an effective antioxidant against pro-oxidant effects of urate. Eur J Biochem 271, 1991-1999.

56. Joubert E, Winterton P, Britz TJ, et al. (2005) Antioxidant and pro-oxidant activities of aqueous extracts and crude polyphenolic fractions of rooibos (Aspalathus linearis). J Agric Food Chem 53, 10260-10267.

57. Acin S, Navarro MA, Arbones-Mainar JM, et al. (2006) Hydroxytyrosol administration enhances atherosclerotic lesion development in apo $\mathrm{E}$ deficient mice. J Biochem 140, 383-391.

58. Surra JC, Guillen N, Barranquero C, et al. (2010) Sexdependent effect of liver growth factor on atherosclerotic lesions and fatty liver disease in apolipoprotein $\mathrm{E}$ knockout mice. Histol Histopatbol 25, 609-618. 